\title{
Uma Experiência Popular de Educação o Fórum Gaúcho da Juventude
}

\author{
Paulo Alfredo Schönardie ${ }^{1}$ \\ Liria Ângela Andrioli ${ }^{2}$
}

\begin{abstract}
Resumo
0 tema deste artigo tem em seu cerne a experiência popular de educação construída pela juventude com o Fórum Gaúcho da Juventude (FGJ). A reflexão parte da hipótese de que jovens protagonizaram um espaço educativo privilegiado na construção e vivência do FGJ. Para compreender a problemática proposta, apresentamos, primeiro, a conjuntura social, premida por uma realidade neoliberal que originou o evento; posteriormente, um breve histórico do mesmo, para, na sequência, pautar teoricamente a categoria juventude. Esses aprofundamentos nos permitem finalmente tecer o contexto educativo popular de práxis vivenciado pelos protagonistas da experiência do FGJ. Metodologicamente são importantes as experiências de educação e trabalho dos pesquisadores, bem como sua participação no evento e o diálogo com os teóricos da educação e da juventude. Conclusivamente, observa-se que os envolvidos com 0 evento se educaram em um processo de práxis.
\end{abstract}

Palavras-chave: Educação. Educação popular. Juventude. Práxis.

\section{A POPULAR EDUCATIONAL EXPERIENCE: The Youth Gaucho Forum}

\begin{abstract}
The subject of this article has in its core the popular experience of education built by youth with the Youth Gaucho Forum (Fórum Gaúcho da Juventude - FGJ). The reflection starts with the hypothesis that young people starred a privileged educational space in the construction and experience of FGJ. To understand the issue proposed, firstly, we present the
\end{abstract}

1 Doutor em Ciências Sociais (Dr. phil.) pela Universität Hamburg - UHH, Alemanha. Professor Pesquisador de Pós-Doutorado com bolsa PNPD/Capes no Programa de Pós-Graduação em Educação nas Ciências da Universidade Regional do Noroeste do Estado do Rio Grande do Sul - Unijuí. pschonardie@gmail.com

2 Doutora em Educação nas Ciências pela Universidade Regional do Noroeste do Estado do Rio Grande do Sul - Unijuí e professora da Universidade Federal da Fronteira Sul - UFFS. liriaandrioli@yahoo.com.br 
social conjuncture, pressed by a neoliberal reality, which originated the event. Afterwards, a brief background thereof, in order to, in sequence, characterize theoretically the category youth. These insights allow us finally to compose the popular educational context of praxis experienced by the protagonists of FGJ practice. Methodologically are important the researchers' experiences of education and work, as well as their participation in the event and the dialogue with theorists of education and youth. Conclusively, it is observed that those involved with the event were educated in a praxis process.

Keywords: Education. Popular education. Youth. Praxis. 
Os seres humanos se educam nos espaços sociais em que vivem. Eles são influenciados pelo meio e pelas pessoas circundantes, mas, ao mesmo tempo, suas ações individuais e coletivas agem sobre o contexto, seja ele físico ou social. Ou seja, os seres se constituem, conforme Schönardie (2014), em um processo educativo histórico e cultural. O humano "sente, pensa, age, imagina, deseja, planeja" (SCHÖNARDIE, 2014, p. 11) e, dessa forma, não apenas se adapta à natureza, mas a transforma, e, ao transformá-la, transforma a si mesmo (MARX, 2008, p. 192). Em algumas situações, tais como na ação coletiva e/ou em sua fase juvenil, isto é, quando seu estágio de formação mental é mais intenso, a aprendizagem é potencializada. Dessa realidade emerge a importância do período humano juvenil e, consequentemente, das ações e/ou eventos coletivos protagonizados pelos jovens em espaços geográficos e culturais. Nessas situações se configura organicamente um espaço privilegiado de educação popular, em que os sujeitos envolvidos passam a ser "os construtores da sua própria história de libertação" (PALUDO, 2001, p. 99).

A importância e a potencialidade das juventudes em construir outra sociedade possível a partir do presente e em sua ação, que é educativa, faz emergir a problemática central desta sistematização. A juventude e sua ação de práxis coletiva e educativa com o FGJ passam a ser a essência a ser problematizada. É necessário, assim, aproximar-se do FGJ bem como aprofundar a conceituação de juventude para, então, perceber a construção de um "possível melhor" pela perspectiva educativa popular.

Partimos da hipótese de que a juventude protagonizou um espaço educativo privilegiado na construção e vivência do FGJ. Os participantes e a sociedade em geral, pela ação direta e/ou indireta com o FGJ, foram instigados a perceber os jovens como categoria social presente e atuante, que, pela práxis, manifestaram e efetivamente arriscaram passos em direção a utopias pessoais e sociais em uma conjuntura social coagida entre o panóptico de controle (FOUCAULT, 1977) em uma região interiorana do Brasil e uma avalanche consumista neoliberal cunhada pelo termo "globalização". A juventude, mesmo influenciada pela geração detentora do poder, construiu seu presente agindo e abriu perspectivas futuras e, ao mesmo tempo, sua ação transgrediu questionando a uniformidade 
global e influenciando sobre a comunidade local. Pela práxis em seu meio, os jovens construíram experiências educativas com o FGJ, que se constituiu como experiência popular de educação.

As iniciativas dos diversos grupos sociais e o estudo com foco na juventude possuem profundas raízes na tessitura social. Tanto elementos locais quanto de espectro mais amplo, ou seja, ligados à sociedade mais ampla, em rede (CASTELLS; CARDOSO, 2005), influenciam nas práticas individuais e coletivas. O FGJ foi, assim, também resultado das profundas transformações vividas pela sociedade brasileira na década de 1990, impulsionadas pela crise dos anos 1980, esta, por sua vez, herdada de um regime autoritário, assim como por uma conjuntura internacional em um período em que o modo de produção capitalista em sua forma excludente se sobrepôs às conquistas sociais históricas.

Também na região interiorana, de bases agrárias, do Noroeste do Estado do Rio Grande do Sul, local onde ocorreu o FGJ, as mudanças históricas e conjunturais foram sentidas, e de uma forma tácita. Desde os anos 60 do século 20 a região em foco foi uma das precursoras mundiais da mudança produtiva-conservadora no setor agrário. A modernização da agricultura local (SCHÖNARDIE, 2013), inserida no movimento avassalador do capitalismo transnacional, provocou também combalimentos sociais. Um quadro de maior separação e exclusão de camadas sociais e também de estreitamento dos horizontes para as juventudes locais, que, por décadas, se constituiu no processo do êxodo do campo para a cidade e do inchamento das periferias pobres de pequenos centros urbanos, foi um dos resultados mais nefastos.

Obviamente a juventude do Noroeste do Rio Grande do Sul também foi às ruas participar dos movimentos que ousaram provocar mudanças no cenário nacional, tais como as "diretas já" e o movimento dos "caras pintadas". Essas experiências, porém, foram silenciadas pela difícil conjuntura dos anos 1990, que, por um lado, praticamente sepultava as possibilidades camponesas locais para os jovens e, por outro, com a crise neoliberal global, fez com que grande parte das juventudes perdesse muitas de suas esperanças no presente e no futuro. 
Os movimentos sociais com base na juventude tiveram de reconstruir suas bandeiras de luta. A nova situação de deserdados rurais e a condição de marginalidade e exclusão perante o capitalismo globalizante provocaram nos movimentos juvenis e sociais, de forma ampla, a difícil tarefa do reconhecimento de sua condição de oprimidos (FREIRE, 1987), para, a partir da realidade, ensaiarem reações. As gerações tiveram de se reeducar e procuraram novos caminhos de ação, de retomada das utopias, para, posteriormente, poder dar passos efetivos para recuperar seu protagonismo.

A partir do final dos anos 1990, e sobretudo com o início do novo milênio, os movimentos sociais conseguiram efetivamente rearticular-se e transformaram-se em forças fundamentais de mudança social e de experimentação de novos caminhos, tanto em âmbito local quanto nacional e internacional. Essa reação foi efetivada em dois grandes campos distintos, mas profundamente interligados. Por um lado, sucederam-se ascensões democráticas dentro dos marcos legais, conduzindo representantes do campo democrático popular (PALUDO, 2001) a mandatos políticos e públicos, organizando-se, consequentemente, em governos populares. Por outro lado, deu-se a reemergência dos movimentos sociais, tais como os metalúrgicos, os trabalhadores rurais, o Movimento dos Trabalhadores Sem Terra (MST), os movimentos de mulheres, de negros, de ambientalistas, os movimentos antiglobalização e das organizações juvenis. A reemergência dos movimentos sociais foi decisiva para a ascensão do campo democrático popular, da mesma forma que essa ascensão contribuiu decisivamente para o avanço dos movimentos sociais. O FGJ é parte dessa conjuntura.

Os movimentos sociais, aliados aos governos populares, fizeram do Estado do Rio Grande do Sul o palco inicial da articulação conjunta objetivando “outro mundo possível”, perante a avalanche liberal, vivenciada pelo neoliberalismo. O Fórum Social Mundial (FSM), em Porto Alegre, foi a manifestação da reação utópica de indivíduos, coletivos, movimentos sociais e governos populares. O FSM foi, ao mesmo tempo, ação e irradiação de iniciativas nas longínquas regiões interioranas. Constituiu-se, assim, um espaço educativo concreto e abstrato, e influenciou o ideário daqueles e daquelas que participaram de forma direta ou indireta de sua caminhada. 
A partir da realização do FSM, os indivíduos e coletivos passaram a propor "fóruns" pelo mundo. Neles começaram a ser refletidas as realidades locais em sua tessitura com a globalidade. O FGJ, aqui objeto reflexivo, foi protagonizado, nessa perspectiva de luta, por uma sociedade mais justa.

É importante destacar introdutoriamente, também, que a presente sistematização é resultado de pesquisas dos autores ainda em andamento dentro dos grandes campos da educação e da educação popular, dos movimentos sociais e da reflexão educativa a partir e com esses movimentos, com destaque aos movimentos da juventude. É de suma importância destacar que tanto a autora quanto o autor desta reflexão participaram do FGJ desde seu início como organizadores do evento e, agora, 12 anos após a primeira edição do FGJ, propõem-se a refletir também criticamente sua ação. Consideramos importante recuperar a história e o protagonismo de luta dos jovens em prol de uma utopia comum, pois observamos, desde 2013, novas manifestações de jovens, sobretudo em cidades populosas, mas, como destaca Barbosa (2014), sem uma pauta definida e inclusive com confrontos violentos de objetivos (CRUZ, 2013, p. 7), ou seja, sem vislumbrar uma utopia. Assim, tanto a comunidade acadêmica quanto a sociedade em geral poderão colher os resultados da pesquisa para, mais uma vez, avançar na reconstrução socialmente justa.

Busca-se, também, o auxílio da comunidade argumentativa por meio de revisão bibliográfica e da experiência vivida pelos pesquisadores, mediante assessorias e trabalhos com os movimentos sociais e os movimentos de juventude. O presente trabalho é, assim, resultado de uma reflexão que Pelinka (2004, p. 1516) aponta como empírico-analítica ao mesmo tempo em que é crítico-dialética.

Torna-se importante apresentar na sequência um breve histórico do FGJ. Posteriormente, aprofundaremos reflexivamente a conceituação da categoria juventude que permitirá tecer, em momento posterior, o contexto educativo popular de práxis vivenciado pelos protagonistas da experiência do FGJ.

\section{Breve História do Fórum Gaúcho da Juventude}

Para recuperar a história do FGJ recorremos basicamente à memória, pois, mesmo sendo um acontecimento contemporâneo, a efervescência juvenil da realização do evento não se ateve à produção de registros escritos. Embasamo- 
-nos na memória tal como Jacques Le Goff (2003, p. 419), percebendo-a “como propriedade de conservar certas informações (...), graças às quais o homem pode atualizar impressões ou informações passadas, ou que ele representa como passadas". Com a presente análise descritiva, quem sabe seja possível produzir uma atualização do FGJ e do aprendizado adquirido com ele. A partir da oralidade, propomos "construir uma memória coletiva escrita" (LE GOFF, 2003, p. 470).

Entendemos a história do FGJ em seis momentos distintos, mas profundamente entrelaçados: a conjuntura que antecedeu o evento; as reuniões e ações que prepararam os encontros propriamente ditos; o encontro presencial, ou materialização do evento; o alcance do ideário a aquelas e aqueles que não participaram presencialmente do encontro materializado; a contribuição com a formação dos participantes, que entendemos ser o principal legado do FGJ e que analisaremos profundamente mais adiante; e o estágio que se inicia com a construção de uma memória coletiva escrita para a posteridade.

No âmbito da conjuntura antecedente ao FGJ, como já exposto anteriormente, havia uma premência local, oriunda do processo de modernização da agricultura, que estava em seu auge em razão do aprofundamento causado pela crise neoliberal, que deixava em brumas mesmo as esperanças das gerações. Perante a dura realidade, movimentos sociais e todo o campo democrático popular organizaram reações, que tiveram uma espécie de cume com a realização do FSM. O alcance do ideário alternativo proposto pelo FSM foi, assim, decisivo para a realização do FGJ.

O primeiro movimento efetivo, em forma de debate, ocorreu na véspera do tempo pascal do ano de 2003, em uma sala de reuniões da Secretaria Municipal de Educação e Cultura do município de Três de Maio, na região interiorana e rural do Noroeste do Estado do Rio Grande do Sul. O município estava sob a gestão de um governo popular, que incorporou em seus quadros indivíduos comprometidos com a reação aos auspícios liberais e, ao mesmo tempo, procurou integrar as pessoas e as organizações sociais. Os integrantes do debate, poucos dias antes, haviam retornado do III FSM, inspirados, sobretudo, pela experiência do Acampamento Intercontinental da Juventude. Sucedeu-se, en- 
tão, já na semana seguinte, o chamamento e a agregação de diversas entidades, inicialmente regionais, posteriormente estaduais e até de abrangência nacional e internacional.

É importante refletir sobre o fato de que o FGJ não partiu diretamente das organizações representativas da juventude, mas sim de um reduzido número de pessoas preocupadas com a geração jovem. Nem todos esses primeiros envolvidos com o evento eram jovens. Essa realidade traz imediatamente à pauta a delimitação da categoria juventude, que será aprofundada a seguir. É necessário destacar que, mesmo a ideia do FGJ tendo surgido de um reduzido número de pessoas participantes do primeiro debate, ela não perde por isso em legitimidade, posto que logo se transformou em evento que efetivamente congregou significativo número de pessoas, entre jovens e população em geral. Os jovens logo perceberam o evento como espaço no qual efetivamente poderiam se tornar protagonistas. É de se destacar que as origens do FGJ se assemelham ao início do FSM. É fato que o pontapé inicial do FSM foi dado em uma conversa entre reduzido número de pessoas, que se reuniram para discutir o que se poderia fazer socialmente para congregar os movimentos existentes no Brasil. ${ }^{3}$

Tal como havia acontecido com o FSM, a iniciativa do FGJ logo ganhou corpo. A primeira ideia de efetivar uma ação para a juventude imediatamente transformou-se em ação com a juventude, em que esta passou a assumir os debates, participando ativamente do processo de organização. De um lado estavam entidades dirigidas por jovens, tais como diretórios acadêmicos, grêmios estudantis, pastorais da juventude, grupos de jovens de sindicatos, etc., de outro, organizações com preocupações com a juventude, tais como governos populares, instituições de ensino, inclusive a universidade, cooperativas, etc. Emerge disso um dos grandes méritos do evento: o diálogo entre gerações.

\footnotetext{
3 Um dos autores desse artigo, que esteve presente no primeiro debate para a criação do FGJ, também participou, em maio do ano de 2013, na cidade de Hamburg na Alemanha, de uma reunião entre organizadores do FSM e entidades internacionais financiadoras do evento. Nessa reunião estava presente uma das pessoas que participou da primeira conversa para a realização do FSM, que relatou minuciosamente os bastidores do surgimento da ideia e da ação do FSM.
} 
As reuniões e ações que prepararam o evento propriamente dito duraram aproximadamente cinco meses. Em plenárias semanais, os representantes das entidades agregadas teceram minuciosamente o primeiro FGJ previsto para o mês de outubro daquele ano. No decorrer desses debates e articulações, sempre novos protagonistas foram se agregando. Também, a simpatia e o reconhecimento dessas ações fizeram com que várias entidades destinassem valores financeiros para viabilizar o evento, destacando-se, inclusive, substancioso repasse do governo federal, que também possuía integrantes do campo democrático popular.

O FGJ propriamente dito teve três edições em anos seguidos, isto é, entre os anos de 2003 e 2005 . A primeira e a segunda edição aconteceram no município de Três de Maio e a terceira no de Cruz Alta. Foi prevista uma quarta edição para ser realizada em Ijuí; essa, entretanto, não se concretizou. Entendemos, contudo, que, mais importante do que o evento presencial em si, o envolvimento no período de preparo às edições foi o mais construtivo. Nele os jovens tiveram a oportunidade de se tornar protagonistas, ou seja, puderam, a sua maneira, delinear e assumir sonhos. O sonho de transformar a sociedade esteve presente em todos os momentos. Os participantes estavam tomados pela utopia de um mundo melhor, de uma boa possibilidade melhor para as juventudes. Queriam provocar a mudança em seu meio de vida. A Carta de Princípios da primeira edição, coletivamente consensuada durante as sucessivas plenárias, retrata claramente esses objetivos. A conjuntura social adversa e a ação dos jovens sobre a situação para tecer alternativas, é tacitamente defendida.

Como espaço de debates, o Fórum Gaúcho da Juventude é um movimento de idéias que estimula a reflexão e a disseminação transparente dos resultados dessa reflexão sobre os mecanismos e instrumentos da dominação do capital, sobre os meios e ações de resistência e superação dessa dominação, sobre as alternativas propostas para resolver os problemas de exclusão e desigualdade social que o processo de globalização capitalista, com suas dimensões racistas, sexistas e destruidoras do meio ambiente está criando, internacionalmente e no interior dos países (FÓRUM..., 2003). 
Pautados pela Carta de Princípios e com temáticas específicas coletivamente definidas, o caminho levou todos ao evento concreto propriamente dito; o primeiro, entre os dias $1^{\circ}$ e 4 de outubro de 2003. Este, no intuito de resolver as aflições dos participantes e do mundo, foi organizado em cinco eixos temáticos: educação e cultura; política: participação e democracia; trabalho e emprego; desenvolvimento sustentável; e, família, violência e sexualidade. As atividades principais nesses eixos temáticos consistiram na realização de conferências com referentes assuntos sugeridos pelos jovens, sobretudo a partir de seu contato com o meio universitário. Ademais, as entidades participantes organizaram diversas oficinas com temáticas que vinham ao encontro dos anseios da juventude. Também atividades culturais, com apresentações de peças teatrais e de bandas, foram estruturadas pelo comitê organizador. A dinâmica, oriunda do $\mathrm{I}^{\circ} \mathrm{FGJ}$ em realizar conferências temáticas, oficinas e atividades culturais, estendeu-se para a programação da $\mathrm{II} 2^{\circ}$ e III $3^{\circ}$ edições.

A estadia doa juventudes jovens durante o evento se deu no Acampamento da Juventude, organizado aos moldes e com inspiração no Acampamento Intercontinental da Juventude do FSM. No Acampamento da Juventude entendemos ter acontecido o momento mais importante e construtivo de práxis, de protagonismo juvenil e de construção de consciência, tal como Freire (1992) a propõe. Espontaneamente, os participantes do Fórum, durante as madrugadas, acenderam uma fogueira em meio as suas barracas e provocaram debates democráticos em favor de outra sociedade possível, tanto para a juventude quanto para a humanidade.

Muito além do processo de construção do FGJ, bem como do evento propriamente dito, foi o alcance do ideário proposto. Trata-se da repercussão criada por essa iniciativa. Por exemplo, nos municípios, onde se realizaram as edições do evento, acredita-se que a maioria dos moradores tenha tomado conhecimento dessa atividade e de suas utopias. A abrangência do anúncio provocado pela difusão da iniciativa, seja pelos meios de comunicação de massa, seja pelos esforços de difusão da organização por meio das entidades que a compunham e 
que levaram o debate para as suas bases, ou pelos conteúdos discutidos, fez com que muitos, mesmo estando a grandes distâncias, tomassem ciência do processo que se passou no encontro propriamente dito, ou, ainda, no preparo do evento.

O FGJ foi um dos poucos eventos de sua época em que a juventude efetivamente assumiu o controle e, ao mesmo tempo, projetou protagonistas em sua ação na posteridade. Não há consenso, entretanto, sobre a categoria juventude. Muitas são as interpretações e posições sobre sua definição. Por isso é necessário, sem querer esgotar a temática, aprofundar as contradições da "delimitação" de juventude.

\section{Juventude: categoria de espírito ou limitação de idade}

Durante os debates das edições do FGJ, uma das temáticas transversais que esteve na pauta fazia constantemente referência ao que se entende por juventude. Inicialmente, duas correntes interagiam na pauta do tema: a dos que viam a juventude como uma categoria de idade e a dos que viam a juventude como um estado de espírito. Nesse sentido, faz-se necessária uma breve conceituação teórica acerca da concepção de juventude, destacando aspectos já debatidos amplamente no FGJ.

Ao analisarmos a primeira categoria, a da idade, vemos que, ao longo da História, procura-se ligar a juventude a um determinado tempo de vida ou então a uma faixa etária específica, classificando-a, geralmente, entre 15 e 24 anos de idade. Segundo Knauth e Gonçalves (2006, p. 95),

em alguns estudos mais atuais ainda se encontra um subproduto dessa essencialização da juventude, em que ela e a adolescência são operacionalizadas cronológica e "naturalmente", limitando-se as faixas etárias pelas características psi e fisiológicas, em geral confinadas entre os 10 e os 19 ou 24 anos.

Nesse viés, a condição juvenil é dada pelo fato de os indivíduos estarem vivendo um período específico de sua vida, ou seja, "o jovem tem sido enquadrado na categoria de ser em formação, em crescimento, em desenvolvimento" (COIMBRA; NASCIMENTO, 2003, p. 19). É necessário, no entanto, levar em 
consideração que essa transição da infância para a vida adulta envolve fatores psicológicos e sociais que variam de acordo com cada indivíduo. Dessa forma, não podemos simplesmente fazer um recorte objetivo da figura do jovem, pois há diferenças consideráveis se formos analisar as classes sociais distintas a que pertencem esses jovens, dos seus estilos de vida, das relações de gênero, etc.

Para os que não têm direito à infância, a juventude começa mais cedo. E, no outro extremo - com o aumento de expectativas de vida e as mudanças no mercado de trabalho -, uma parte "deles" acaba por alargar o chamado "tempo da juventude" até a casa dos 30 anos. Com efeito, qualquer que seja a faixa etária estabelecida, jovens com idades iguais vivem juventudes desiguais (NOVAES, 2006, p. 105).

Já a categoria que classifica a juventude como um "estado de espírito" apresenta-se como a unificação de todas as características comuns aos jovens. Dá a entender que existe somente uma juventude, que pensa e age da mesma forma, tal como a sociedade a classificou: rebelde, irresponsável, revolucionária.

Dessa maneira, "qualidades" e "defeitos" considerados típicos do jovem, como entusiasmo, vigor, impulsividade, rebeldia, agressividade, alegria, introspecção, timidez, passam a ser sinônimos de uma natureza jovial (COIMBRA; NASCIMENTO, 2003, p. 20).

Com base nessas reflexões acerca da concepção de juventude, desencadeou-se também o debate em torno do reconhecimento e da autonomia dos jovens como atores sociais, sendo os mesmos agentes de transformação e protagonistas de sua própria história. O próprio evento do FGJ constantemente se reafirmava, tendo os jovens como envolvidos diretamente nesse processo. Nesse sentido, podemos caracterizar o protagonismo juvenil com base em

ações juvenis coletivas e participantes - nelas se constroem a autonomia dos participantes e o envolvimento da coletividade com a ação. Esse modelo de ação, por conseguinte, não supõe um mecanismo de geração de lideranças individuais, indivíduos líderes (elites), mas a geração de participação e cooperação social. Propriamente, protagonismo é um modelo pedagógico-político 
de ação. É uma ação educativa que relaciona jovens e educadores - ou somente jovens - na construção de um processo de intervenção sociocultural (IULIANELLI, 2003, p. 71).

A discussão em torno da concepção de juventude que se deu no FGJ reafirmou a importância de os jovens serem protagonistas das suas ações, e que os mesmos tenham voz ativa no processo de transformação da sociedade. Mais do que isso, os jovens assumiram efetivamente, pela práxis, o FGJ e a concretização de utopias. Em sua ação constituíram espaço educativo privilegiado.

\section{A educação no processo de práxis popular}

Todo processo criado em torno da concretização do FGJ insere-se na pedagogia da práxis, que "é a teoria de uma prática pedagógica que procura não esconder o conflito, a contradição, mas, ao contrário, os afronta, desocultando-os" (GADOTTI, 2004, p. 28). Os atos pedagógicos que perpassam as ações dos protagonistas do FGJ, analisados pela sua ação de práxis, carregam em si processos históricos, o que evidencia seu sentido dialético. Inscrevem-se a um "ato de conhecer [que] envolve um movimento dialético que vai da ação à reflexão sobre ela e desta a uma nova ação" (FREIRE, 1982, p. 50).

A partir de um contexto de práxis, a centralidade do processo educativo no FGJ estava dada nos sujeitos, o que nos remete à perspectiva popular de educação, ou seja, à educação popular que tem, entre suas características, "acompanhar o movimento da sociedade, buscando sempre novos espaços para sua realização" (STRECK, 2013, p. 356). O movimento popular do FGJ carrega consigo a busca por alternativas vividas por indivíduos e coletivos em um contexto adverso (SCHÖNARDIE, 2015, p. 2). A educação, em suaseu matiz popular, se manifesta, assim, pela sua vocação de resistência (BRANDÃO, 2013, p. 12) e, ao mesmo tempo, pela construção de alternativas, no caso, perante a aproximação entre problemas de exclusão locais e a realidade neoliberal. Nessa perspectiva, o espaço educativo, protagonizado pelo FGJ, configurou-se como lugar de construção social coletiva (TORRES, 2008). 
A práxis evidenciada e vivida pelos participantes do processo educativo, construtor de aprendizagens sociais, se deu em um cotidiano de conflitos, ações, contradições e necessidades, levando em consideração a caminhada histórica dos sujeitos envolvidos bem como a conjuntura social. As constantes reuniões e plenárias, a pauta programática, o próprio formato do sentido de um fórum, os debates ao redor da fogueira no Acampamento da Juventude, entre outros, se sucederam em valorosos debates, os quais faziam repensar as ações cotidianas dos participantes. Esses debates permeavam uma "ruptura com alguma coisa, com preconceitos, com hábitos, com comportamentos, etc." (GADOTTI, 2004, p. 29). Essas mudanças, mesmo carregadas de conflitos, fizeram com que os participantes jamais fossem os mesmos no decorrer de suas vidas. O reconhecimento da alteridade, por uma categoria que se assumia, qual seja, a juventude, provocou um processo de diálogo entre os participantes e desses com a sociedade. São "outros sujeitos", nomeadamente a juventude comumente excluída dos processos constituídos, que constroem "outras pedagogias” (ARROYO, 2014).

A vivência dos protagonistas do FGJ evidencia que o ser humano "é um ser da 'práxis'; da ação e da reflexão" (FREIRE, 1992, p. 28). Nas relações com o mundo, "através de sua ação sobre ele, o homem se encontra marcado pelos resultados de sua própria ação" (FREIRE, 1992, p. 28). A vivência no FGJ fez dos participantes protagonistas de um processo educativo e transformou o evento em um movimento, criando uma realidade envolvente, em que os sujeitos foram, conforme Marx (2008), recebendo influências em processo, mas ao mesmo tempo reconstituindo o contexto e a si próprios. Pela práxis se construiu a emancipação juvenil, efetivamente "produzindo" sujeitos populares "capazes de serem os construtores de sua própria história de libertação" (PALUDO, 2001, p. 99).

As vivências dos sujeitos com o FGJ se inscrevem, assim, em um contexto de constituição humana pela matriz educativa histórico-cultural. Os seres humanos, desde tenra idade, tendem a construir socialmente o seu processo pessoal de, inicialmente, adaptação ao meio social, e, posteriormente, intervenção pela 
sua ação (VIGOTSKI, 2000; REGO, 1995). Nesse sentido, a adaptação ao meio social de vivência traz consigo também as tradições culturais, que, no transcurso da História, vão se tornando complexas (TOMASELLO, 2003, p. 51).

Obviamente, como observado anteriormente a partir de Gadotti (2004), esse novo espaço educativo não se dá sem conflito. A sociedade estrutura e formaliza os processos educativos "em função dos interesses de quem tem o poder" (FREIRE, 1982, p. 146). Na conjuntura histórica do FGJ, o status quo a ser preservado é o da cultura neoliberal. A ruptura protagonizada pela juventude se dá exatamente perante essa conjuntura e, ao mesmo tempo, ante a opressão a que é relegada pelo modelo bancário de ensino (FREIRE, 1987).

Nesse sentido, o FGJ também rompeu com os processos educativos apenas formais, ou seja, aqueles estruturados pelos sistemas oficiais de ensino. As vivências sociais e educativas com o FGJ se deram, assim, basicamente no campo educativo não formal. Gohn (2005) e Libâneo (2004) definem a modalidade educativa não formal como aquela que apresenta, sim, algum tipo de planejamento sistematizado, mas oriundo do grupo social em que acontece, ou seja, as questões em pauta provêm das necessidades e interesses de seus protagonistas, no caso a juventude.

Pela reflexão até aqui realizada, nos parece possível admitir consensuadamente que todas as vivências humanas têm carga educativa. Brandão (1981, p. 7) nos ensina que "ninguém escapa da educação". O FGJ se constrói como espaço e vivência educativa popular

a partir de uma crítica indignada da ordem social dominante e a partir da identificação com visões de futuro alternativas, busca contribuir para a constituição de diversos setores subalternos como sujeitos de transformação, incidindo em diferentes âmbitos de sua subjetividade, mediante estratégias pedagógicas dialogais, problematizadoras, criativas e participativas (TORRES, 2013, p. 19).

O FGJ teve, assim, uma intencionalidade política emancipadora (TORRES, 2008, p. 13), e efetivamente a juventude e a sociedade com que essa intencionalidade interagiu, seja durante o evento, seja nas suas vivências posteriores, 
construiu e continua construindo um caminho que se aproxima ao sonho de uma vida e de uma sociedade melhores, ou seja, uma aproximação efetiva da utopia de outro mundo possível.

\section{Algumas considerações}

Primeiramente precisamos considerar que a reflexão aqui proposta é orientada por uma questão de pesquisa, problematizada e balizada pelo olhar científico de uma hipótese. Por isso, em nenhum momento temos a pretensão de esgotar os estudos relativos ao FGJ. Por outro lado, estamos cientes da responsabilidade de termos, pela primeira vez, procurado analisar criticamente

um acontecimento do qual fomos protagonistas. É esse aprofundamento que nos permite perceber que, colocando em pauta algumas categorias, tais como juventude, conjuntura do FGJ e sua relação com o processo educativo, acabamos nos fazendo mais questionamentos, os quais aguçam a necessidade de maiores aprofundamentos sobre o tema.

Entendemos que pautando a experiência popular de educação tecida pelo FGJ temos o potencial de contribuir com as ciências humanas e educacionais, mais especificamente com os estudos posteriores que venham a pautar o FGJ, a juventude de forma ampla, a Região Noroeste do Rio Grande do Sul, a relação entre educação e juventude, a educação popular e a própria História e, mais do que isso, contribuir com a sociedade.

Vimos que o FGJ foi uma reação da juventude e da sociedade a condições adversas impostas, por um lado, pela realidade de exclusão e falta de perspectiva local, oriunda de uma profunda crise do modelo agrário local e seus êxodos, entre os quais, o rural e o cultural; por outro, reação à determinante conjuntura neoliberal, que tentava inclusive silenciar as utopias das gerações mais novas. A juventude e a sociedade local reagiram, protagonizando ações políticas no campo democrático popular, conquistando governos e fazendo deles espaços de ações populares e, ao mesmo tempo, se inserindo nos movimentos sociais populares, congregando-os, por exemplo, no FSM e construindo-os com o FGJ. 
O movimento protagonizado pela juventude com o FGJ não foi linear, não aconteceu sem conflitos de ideias e teorias. Precisou impor-se dialogando com as gerações detentoras do poder e também consigo mesmo. A categoria juventude esteve em pauta a todo momento. O questionamento relativo à definição de juventude por idade ou por estado de espírito sempre acompanhou o FGJ de forma transversal. Em nenhum momento se chegou a uma conclusão, assim como está em aberto o aprofundamento teórico suprarrealizado. Os jovens, cada qual com sua definição de si, porém, fizeram o FGJ acontecer, mas dialogando para se aceitar nos diferentes espaços.

O ponto de partida do estudo foi a hipótese de que a juventude protagonizou um espaço educativo privilegiado na construção e vivência do FGJ. Pudemos, efetivamente, constatar que a tese inicial é uma realidade. Os jovens e a sociedade em geral que participaram do evento engajaram-se na luta por uma sociedade melhor, uma sociedade em que a juventude também fosse protagonista, e nas ações vividas com o FGJ os participantes assumiram efetivamente a condição de delineadores, de atuantes, tomando suas próprias decisões e as colocando em prática. Essa experiência educativa abriu também perspectivas futuras de inserção e atuação.

Os participantes se tornaramatuantemente sujeitos de sua História, se educaram pela práxis e por ela construíram consciência, vivenciando, assim, um processo de educação popular. Obviamente também foram influenciados pelo meio social, mas com suas ações agiram sobre este, transformando-o e transformando a si mesmos.

As mudanças na vida dos participantes foram significativas. Por isso entendemos que seria muito importante que as juventudes pudessem constantemente construir seus fóruns, em todos os lugares e a sua maneira, cometendo erros e acertos, com os quais se constituiriam pela práxis. Pudemos constatar que todos os participantes/protagonistas do FGJ reconstruíram seu pensamento e ação. Pela vivência educativa em processo, eles se educaram buscando caminhos na direção das utopias. 


\section{Referências}

ARROYO, Miguel G. Outros sujeitos, outras pedagogias. Petrópolis: Vozes, 2014.

BARBOSA, Liége F. Jovens e movimentos sociais no Brasil. Interrogando significados das manifestações de junho de 2013. ANPED SUL, 10., 2014, Florianópolis. Anais... Florianópolis: Anped Sul, 2014.

BRANDÃO, Carlos R. Prefácio. Cinquenta e um anos depois. In: STRECK, Danilo R.; ESTEBAN, Maria T. Educação popular. Lugar de construção social coletiva. Petrópolis: Vozes, 2013.

. O Que é educação. São Paulo: Brasiliense, 1981.

CASTELLS, Manuel; CARDOSO, Gustavo. A sociedade em rede. Do conhecimento à acção política. Lisboa: Imprensa Nacional-Casa da Moeda, 2005.

COIMBRA, Cecília M. B.; NASCIMENTO, Maria L. do. Jovens pobres. O mito da periculosidade. In: FRAGA, Paulo C. P.; IULIANELLI, Jorge A. S. (Org.). Jovens em tempo real. Rio de Janeiro: DP\&A, 2003.

CRUZ, Marcio. Fórum de educação popular. Frepop. In: Cartas pedagógicas Ceaal Brasil. Educação popular e juventude. Porto Alegre: Ceaal, 2013.

FÓRUM GAÚCHO DA JUVENTUDE. FGJ. Carta de princípios. Três de Maio: Texto Impresso, 2003.

FOUCAULT, Michel. Vigiar e punir. Nascimento da prisão. Petrópolis: Vozes, 1977.

FREIRE, Paulo. Ação cultural para a liberdade. 7. ed. Rio de Janeiro: Paz e Terra, 1982. . Extensão ou comunicação? 10. ed. Rio de Janeiro: Paz e Terra, 1992. . Pedagogia do oprimido. 19. ed. Rio de Janeiro: Paz e Terra, 1987.

GADOTTI, Moacir. Pedagogia da práxis. 4. ed. São Paulo: Cortez; Instituto Paulo Freire, 2004.

GOHN, Maria da G. Educação não-formal e cultura política. Impactos sobre o associativismo do terceiro setor. 3. ed. São Paulo: Cortez, 2005.

IULIANELLI, Jorge A. S. Juventude. Construindo processos. O protagonismo juvenil. In: FRAGA, Paulo C. P.; IULIANELLI, Jorge A. S. (Org.). Jovens em tempo real. Rio de Janeiro: DP\&A, 2003.

KNAUTH, Daniela R.; GONÇALVES, Helen. Juventude na era da Aids. Entre o prazer e o risco. In: ALMEIDA, Maria I. M. de; EUGENIO, Fernanda (Org.). Culturas jovens. Novos mapas do afeto. Rio de Janeiro: Jorge Zahar, 2006.

LE GOFF, Jacques. História e memória. Campinas: Unicamp, 2003. 
LIBÂNEO, José C. Pedagogia e pedagogos para quê? 7. ed. São Paulo: Cortez, 2004.

MARX, Karl H. Das Kapital. Erster Band. Marx Engels Werke, Bd. 23, 23. Auflage, Berlin: Dietz Verlag, 2008.

NOVAES, Regina. Os jovens de hoje: contextos, diferenças e trajetórias. In: ALMEIDA, Maria I. M. de; EUGENIO, Fernanda (Org.). Culturas jovens. Novos mapas do afeto. Rio de Janeiro: Jorge Zahar, 2006.

PALUDO, Conceição. Educação popular em busca de alternativas. Uma leitura desde o campo democrático popular. Porto Alegre: Tomo Editorial; Camp, 2001.

PELINKA, Anton. Grundzüge der Politikwissenschaft. Wien/Köln/Weimar: Böhlau, 2004.

REGO, Teresa C. Vygotsky. Uma perspectiva histórico-cultural da educação. Petrópolis: Vozes, 1995.

SCHÖNARDIE, Paulo A. Bäuerliche Landwirtschaft im Süden Brasiliens. Historische, theoretische und empirische Studie zu Ernährungssouveränität, Modernisierung, Wiederbelebung und Staatsfunktion. München: Oekom, 2013.

. Educação popular como política pública. Análise crítica. REUNIÃO NACIONAL DA ANPED, 37., 2015, Florianópolis. Anais... Florianópolis: Anped, 2015.

. O processo educativo na perspectiva histórico-cultural. In: Revista Contexto \& Educação, Ijuí: Ed. Unijuí, ano 29, n. 93, maio/ago. 2014.

STRECK, Danilo R. Territórios de resistência e criatividade. Reflexões sobre os lugares da educação popular. In: STRECK, Danilo R.; ESTEBAN, Maria T. Educação popular. Lugar de construção social coletiva. Petrópolis: Vozes, 2013.

TOMASELLO, Michael. Origens culturais da aquisição do conhecimento humano. São Paulo: Martins Fontes, 2003.

TORRES, A. A educação popular como prática política e pedagógica emancipatória. In: STRECK, Danilo R.; ESTEBAN, Maria T. Educação popular. Lugar de construção social coletiva. Petrópolis: Vozes, 2013.

. La educación popular. Trayectoria y actualidad. Bogotá: El Buho, 2008.

VIGOTSKI, Lev S. A construção do pensamento e da linguagem. São Paulo: Martins Fontes, 2000.

Recebido em: 29/9/2015

Aceito em: 29/7/2016 